\title{
Inflation in Pakistan: Empirical Evidence on the Monetarist and Structuralist Hypotheses
}

\author{
FAIZ BILQUEES*
}

In the light of the debate between the monetarists and the structuralists regarding the explanation of inflation in the LDCs this paper tests the monetarist and structuralist hypotheses to determine the possible factors affecting the inflationary process in Pakistan. After examining the two hypotheses the study concludes that in addition to monetary factors, the structural factors peculiar to the economy of Pakistan also have to be considered for a better understanding of this phenomenon.

\section{INTRODUCTION}

Empirical evidence on the monetarist hypothesis shows that generally the monetarist model provides a fairly reasonable explanation of the inflationary process in the LDCs. However, a number of studies, especially those pertaining to the post1970 international economic crisis show that for a systematic analysis of the inflationary process in the LDCs the tests of the monetarist hypothesis needs to be supplemented by a careful consideration of the structural factors affecting the LDCs. ${ }^{1}$ The survey of literature on inflation in Pakistan shows clearly that the monetarist model has not been adequately tested for Pakistan ${ }^{2}$ while the structuralist hypothesis has been completely ignored. The objective of this study is to undertake a simultaneous study of the monetarist and structuralist hypotheses for Pakistan to determine whether the inflationary process in Pakistan is adequately explained by the monetarist hypothesis as postulated by the proponents of the monetarist school or the analysis needs to be further supplemented by a study of the structural factors also as in the case of most of the LDCs.

This paper is divided into seven sections as follows: Section II discusses the monetarist model and gives the specification of the model. Section III describes the

*The author is Research Econiomist at the Pakistan Institute of Development Economics, Islamabad. This paper is a part of the Ph.D.dissertation submitted to the University of Manchester. The author gratefully acknowledges very helpful comments by the two anonymous refrees.

${ }^{1}$ See Faiz B. Firoze (1986, Chapter 3, Section 3.2.2).

${ }^{2}$ See Faiz B. Firoze (1986, Chapter 4, Section 4.5). 
structuralist approach and the specification of the structuralist model. Section IV briefly describes the data sources and their limitations. The results of the two models are analysed in Sections V and VI, and finally Section VII concludes the paper.

\section{THE MONETARIST MODEL: THE QUANTITY THEORY APPROACH}

Most of the studies relating to the explanation of the inflationary process in DCs have adopted the (Harberger 1963) model for Chilean inflation. The Harberger model is essentially an extension of the basic quantity theory framework which relates the rate of inflation $\left(\dot{P}_{t}\right)$ to the rate of growth of money supply $\left(\dot{M}_{t}\right)$, the rate of growth of real income $(\dot{Y})$ and the cost of holding cash $\left(\dot{A}_{t}\right)$. The estimated equation in its simplest form is:

$$
\dot{P}=\dot{M}+\alpha_{1} \dot{Y}+\alpha_{2} \dot{A} \quad \ldots \quad \ldots . \quad \ldots \quad \ldots
$$

where dots on the variables indicate percentage changes.

To facilitate the interpretation of the regression results it is useful to show how this model is related to the quantity theory of money. Equation (1) is derived from the conventional demand for money function of the form:

$$
M^{d}=P_{y}(1+\alpha) A^{-b} \quad \ldots \quad \quad \ldots \quad \ldots
$$

or in terms of real balances, by the homogeneity assumption:

$$
M^{d} / p=Y^{(1+\alpha) A^{-b}}
$$

The monetarist model is predicated upon the existence of a stable demand function for real money balances. Their level is postulated to be a function of the level of real income. In addition, the monetarist model postulates that money supply is exogenous and can be controlled by the monetary authority, and the demand for money, by assumption, tends to equate the supply of money. Therefore, the fundamental symmetry between the demand for money function and the Harberger equation of inflation relates to the central assumption of an exogenous money supply.

Expressing Equation (2) in logarithmic form:
Solving Equation (4) for $\log P$ and taking first differences:

$$
\begin{aligned}
& \Delta \ln P=\Delta \ln M-(1+\alpha) \Delta \ln Y+b \ln A \quad \ldots \quad \ldots \ldots \\
& \text { or } \\
& \dot{P}_{t}=\dot{M}_{t}-(1+\alpha) \dot{Y}_{t}+b \dot{A}_{t} \\
& \text { ‥ } \\
& \text {... } \\
& \text {.. }
\end{aligned}
$$

The absence of a term in front of $\dot{M}$ in Equation (6) implies that the demand for real balances depends on real variables i.e., there is no money illusion and that adjustment is instantaneous. This simple transformation of the liquidity preference function (Equation 6) permits us to express the price level as a function of the quantity of money, the level of real income and the expected cost of holding cash.

The expected signs of the different variables for Equation (6) are as follows:

(a) The rate of inflation is postulated to be positively related to the rate of growth of money supply;

(b) It is postulated to be negatively related to the growth of real income; and

(c) The expected rate of inflation is postulated to be positively related to inflation.

In the traditional liquidity preference formulation the interest rate measured the cost of holding cash for a period, i.e. a yield from alternative use of funds that is foregone when cash is held. In the LDCs where interest rates on bank loans are subject to legal control and generally kept substantially below the rate of inflation, the rates actually paid by the borrowers are typically negative in real terms. The cost of holding cash in the LDCs would be better measured, therefore, by the deterioration in the purchasing power of money - the rate of inflation. In Harberger (1963) and almost all subsequent studies, the rate of change in the expected cost of holding cash is proxied by the difference between the rate of inflation in the past year and the rate of inflation in the year before that $\left(P_{t-1}-P_{t-2}\right)$.

This specification of price expectations is rather arbitrary and simplistic. It ignores the more refined methods of calculating inflationary expectations (adaptive expectations and extrapolative models). In the present study, the adaptive expectations model was used to estimate the expectations variable by accounting for the trend growth underlying the inflation rate (Appendix I). However, because the coefficient turns out to be almost one, the expectations may have been static.

\section{Specification of the Monetarist Model}

The simple version of the price inflation model which does not include the expectations variable is estimated by Equation (7) as:

$$
\dot{P}_{t}=\alpha_{0}+\alpha_{1} \dot{M}_{t}+\alpha_{2} \dot{M}_{t-1}+\alpha_{3} \dot{Y}_{t}+u_{t} \ldots \ldots
$$


where $\dot{P}_{t}$ is the rate of inflation in the current period; $\dot{M}_{t}$ and $\dot{M}_{t-1}$ represent the percentage changes in the money supply in the current and preceding period, $\dot{Y}_{t}$ is the percentage change in real GNP in the current period, and $u_{t}$ is the random error term with constant variance.

The inclusion of the lagged money supply variable $\left(\dot{M}_{t-1}\right)$ is justified on the grounds that the empirical evidence on the monetarist hypothesis shows that for all the LDCs the effects of increase in money supply on the rate of inflation do not occur instantaneously. ${ }^{3}$

In the second version we introduce the inflationary expectations $\left(\dot{p}_{t}^{e}\right)$ amongst the independent variables as a measure of $\dot{A}_{t}$ in Equation (6) as:

$$
\dot{P}_{t}=\beta_{0}+\beta_{1} \dot{M}_{t}+\beta_{2} \dot{M}_{t-1}+\beta_{3} \dot{Y}_{t}+\beta_{4} \dot{P}_{t}^{e}+u_{t} \quad \ldots \quad \ldots
$$

where $\dot{p}_{t}^{e}$ is the expected change in the inflation rate, the rest of the variables are the same as defined above.

We continue to assume $u_{t}$ to be a stationary random process with a constant variance function. It is assumed to be independent of $\dot{M}_{t}$ and $\dot{Y}_{t}$ but not necessarily independent of $\dot{p}_{t}^{e}$. In fact, it will usually not be independent of $\dot{p}_{t}^{e}$ since $\dot{p}_{t}^{e}$ itself is a weighted average of the past $u$ 's. We assume, for simplicity, that the time dependence of the $u$ 's can be adequately represented by the first order auto-regressive scheme, we write:

$$
u_{t}=\rho_{t-1}^{u}+e_{t}
$$

where: $|e|<1$, and $e_{t}$ is white noise.

The structural form (8) is modified to accomodate the auto-regressive process (8a) to yield a restricted transformed equation of the form:

$$
\begin{aligned}
& \dot{P}_{t}=\beta_{0}(1-\rho)+\beta_{1} \dot{M}_{t}+\left(\beta_{2}-\rho \beta_{1}\right) \dot{M}_{t-1}-\rho \beta_{2} \dot{M}_{t-2}+\beta_{3} \dot{y}_{t}-\rho \beta_{3} \dot{y}_{t-1} \\
& +\beta^{4} \dot{p}_{t}^{e}-\rho \beta_{4} \dot{p}_{t-1}^{e}+\rho \dot{P}_{t-1}+e_{t} \quad \cdots
\end{aligned}
$$

An alternative possibility is that the structural form has a misspecified dynamic structure, (in which case auto-correlation arises because of omitted variables), and that the true relationship is a general linear one having all the explanatory variables of the restricted transformed equation but having no non-linear restrictions

\footnotetext{
${ }^{3}$ See Faiz B. Firoze (1986, Chapter 3, Section 3.2.2).
}

among coefficients, i.e. the correct relationship is given by the unrestricted transformed equation of the form:

$$
\begin{aligned}
& \dot{P}_{t}=\gamma_{0}+\gamma_{1} \dot{M}_{t}+\gamma_{2} \dot{M}_{t-1}+\gamma_{3} \dot{M}_{t-2}+\gamma_{4} \dot{Y}_{t}+\gamma_{5} \dot{Y}_{t-1}+\gamma_{6} \dot{P}_{t}^{e}+ \\
& \gamma_{7} \dot{P}_{t-1}^{e}+e_{t}
\end{aligned}
$$

Equations (8) and (10) can be estimated directly by the OLS. However, a direct estimate of Equation (9) is not possible since there is a non-linear restriction between the parameters. It requires an iterative technique to resolve this restriction. Between Equations (9) and (10) we can test the validity of the restrictions which is in effect a test of the correctness of the dynamic specification in Equation (8).

The GIVE package enables us to estimate the three equations simultaneously. The test of $\rho$ in Equation (9) is given by:

(a) The $t$-test for the significance level of the coefficient of $\rho$;

(b) The $\chi^{2}$-test for the significance of $\rho$; and

(c) The $\chi^{2}$-test for the validity of the auto-regressive restrictions.

The test of the significance of the additional parameters in Equation (10) is given by the $F$-test.

The null hypotheses tested are:

(i) $\rho=0$;

(ii) The auto-regressive restrictions are valid; and

(iii) The coefficients of additional parameters are zero.

It is hypothesized that:

(a) If (i) is not rejected in which case (ii) is not relevant, and (iii) is not rejected, then Equation (8) is the appropriate estimated form;

(b) If (i) is rejected and (ii) is not rejected then Equation (9) is appropriate; and

(c) If (i), (ii) and (iii) are all rejected then Equation (10) is the appropriate estimated form.

\section{THE STRUCTURALIST'S APPROACH}

The structuralist theory of inflation in the LDCs emerged as an alternative to the orthodox monetary theory in Latin America in the 1950s after the failure of a number of stabilization programme based on the monetarist approach. The structuralists argued that the aggregate solutions put forward by the monetarists provided temporary relief but accentuated the inflationary pressures in the long run. The basic premise of the structuralist hypothesis is that the inflationary process in the LDCs cannot be adequately explained by reference to the level of aggregate demand. They argue that fragmentation between supplies and demand in and between different sectors of the economy is the root cause of inflation in these economies. 
The structuralists make a distinction between the causes of inflationary pressures and cumulative inflationary pressures on the one hand and the propogating elements on the other. The causes of inflationary pressures, i.e., the basic structural limitations are taken to be: (a) the inelastic food supply in the face of rapidly expanding demand - the agriculture sector bottleneck; (b) the inelasticity and instability of the purchasing power of exports - the foreign exchange bottleneck; and (c) the inelasticity of the tax revenues due to structural deficiencies in the tax system the financial constraint.

According to the structuralists these primary causes of inflation need a propagation mechanism for inflation actually to develop. The propagation mechanism is described as the response of the monetary authorities to the struggle between two major economic groups, i.e., between wage earners and profit earners to maintain their shares in total income; and between private and public sectors to increase their shares of real resources in the face of ensuing inflation. Thus, contrary to the monetarists, the structuralists assign a secondary role to the monetary factors in the inflationary process of LDCs. We examine below some of the possible indicators of the three major structural constraints.

\section{Indicators of Agricultural Supply Bottlenecks}

The agricultural supply bottleneck defined as excess demand in agriculture is quantified by two separate indices. The first involves a relative price measure defined as the annual rate of change of food prices minus the annual rate of change in the cost of living. It is justified on the premise that the theory predicts that a continuous increase in food prices exerts a strong influence on the movement of the overall price index. A second, more direct measure of excess demand, is the difference between the rate of growth of demand for agricultural production minus the rate of growth of agricultural production. In measuring the rate of growth of demand for agricultural production, the elasticity of demand with respect to population growth is assumed to be one, while the income elasticity of demand is approximated at 0.6 .

\section{Indicators of Foreign Exchange Constraints}

Four most commonly used indicators of foreign exchange constraint are the terms of trade index; the import ratio; unit value index of imports and the instability of export earnings. The terms of trade index does not involve any serious problem of reverse causation but it remains unchanged in response to any policy measures like import controls, duties or devaluation provoked by inflation because both import and export prices remain unchanged in foreign currency.

Import ratios as a measure of the foreign exchange constraint is postulated to bear a negative relation to the rate of inflation. If a country experienced a long-term decline in import capacity it could respond by reducing its import ratio over time which exerts an inflationary pressure on prices. Hence, it would be expected that the greater the decline in the import ratio, ceteris-paribus, the larger the rate of inflation. However, if the effects of inflation on the balance of payments could be dampened by import controls rather than by devaluation, the import ratio may fall. On the other hand, at least in the short run, the high rate of inflation may raise the import ratio and low rates of inflation may lower the import ratio.

The unit value index of import prices in domestic currency as an indicator of the foreign exchange constraint is equivalent to an excess demand for imports, which is likely to be reflected in the increase in the unit values of imports in the domestic market. Persistent excess demand, suggested by the worsening of the constraint over time, in turn, implies a sustained upward movement in the import price index.

Instability of export earnings is postulated to be positively related to inflation. However, since there are several theoretical mechanisms underlying this hypothesis and since response to external shocks would tend to vary from country to country, a close relationship between inflation and export variability becomes doubtful.

\section{Indicators of Fiscal Constraint}

The fiscal constraint is usually represented by the budget deficit which is defined as:

(a) Central government total revenues minus total expenditures; and

(b) Public sector deficit as a percentage of GNP.

Also, it is generally argued that in LDCs the instability of revenues is positively related to government budget deficits. Studies by Aghevli and Khan (1978) and Mikesell (1969) which show a positive association between inflation and the budget deficit have defined it as deficit financing by means of credit creation through the banking system.

\section{Specification of the Structuralist Model}

Having reviewed the various indicators of structural bottlenecks and keeping in view the structure of the economy of Pakistan, the model based on the structuralist hypothesis is estimated by Equation (11) as:

$$
\dot{P}_{t}=\beta_{0}+\beta_{1} y_{c_{t}}+\beta_{2} y_{c_{t-1}}+\beta_{3} \dot{P}_{f r}+\beta_{4} \dot{P}_{m_{t}}+\beta_{5} \dot{C}_{g_{t}}+\beta_{6} \dot{P}_{t}^{e}
$$

where $\dot{P}_{t}$ the dependent variable is the rate of inflation; $y_{c_{t}}$ and $y_{c_{t-1}}$ are the percentage deviations of output in the commodity-producing sectors from potential output in the current and previous periods; $\dot{P}_{f r}$ is the percentage change in relative food prices and $\dot{P}_{m_{t}}$ is the percentage change in the unit value index of imports! $\dot{C}_{g_{t}}$ is the percentage change in credit to the government sector. $\dot{P}_{t}^{e}$ is the expectations variable. 
hypothesis that the supply-side constraint, namely a decline in output below the trend would lead to higher inflation. This hypothesis will be tested later in the study.

The results obtained from the model, including the expectations variable, are reported in Table 2. The number of observations is the same as in the first model. On the basis of statistical criteria set out in Section II above, we see that Equation I in Table 2 is the appropriate estimated equation.

Equation I shows that the four arguments of the monetarist model, namely money supply current and lagged, real income and inflationary expectations explain about 65 percent of the observed variation in the rate of inflation in Pakistan. ${ }^{8}$

The coefficient of current money supply continues to bear the incorrect sign and remains insignificant. However, the coefficient of lagged money supply is significant at the 2.5 percent level of significance and the sum of the coefficients of $\dot{M}_{t}$ and $\dot{M}_{t-1}$ is greater than zero. ${ }^{9}$ The coefficient of real income continues to be insignificant and the size of the coefficient is also reduced drastically.

The most important explanatory variable in this equation is that of inflationary expectations. The magnitude of the coefficient is very large and it is highly significant at the 0.1 percent level. The low coefficient for money supply and the highly significant and large coefficient of the expectations variable has important implications. In the absence of the expectations variable the impact of increased money supply on the rate of inflation extends over th.ree years and the size and significance of lagged coefficients increases (Table 1). However, in Table 2 we see that the adjustment of money supply is picked up by the expectations variable; i.e. the value of the sum of money supply coefficients divided by one minus the coefficient of expectations is not different from one. Thus, with the expectations of higher inflation the adjustment period of increased money supply is curtailed and inflation increases at a faster rate than increases in money supply. This outcome has an important implication: the rate of inflation is strongly affected by the expectations of higher inflation implies that in addition to money supply there are other nonmonetary influences also which have exerted a stronger influence on the rate of inflation. This implies that a simultaneous consideration of the structural factors may be important in explaining the inflationary process in Pakistan. Such a consideration is also implied by the negative, although insignificant coefficient, of $\dot{Y}_{t}$ which may be interpreted, a priori, as evidence of the structural hypothesis that the supply-side constraints (namely slow growth in output due to structural rigidities may prevent output from exercising a dampening influence on domestic prices would lead to higher inflation.

${ }^{8}$ Using simply the lagged inflation rate $\dot{P}_{t-1}$ as the proxy for expected rate of inflation yielded an $R^{2}$ of 0.632 when the expected rate of inflation is estimated by the adaptive expectations model without taking into account the trend growth rate $R^{2}$ is 0.73 .

${ }^{9}$ When $\dot{M}_{t-2}$ is introduced to test for the misspecification due to omitted variables it leads to misspecification of the model 


\section{RESULTS OF THE STRUCTURALIST MODEL}

The results of the structuralist model are reported in Table 3. Overall, the results show that price expectations $\left(\dot{P}_{t}^{e}\right)$, the import price indicies $\left(\dot{P}_{m_{t}}\right.$ and $\left.\dot{P}_{m_{t-1}}\right)$ and the trends in the commodity producing sector $\left(y_{c_{t}}\right)$ are the most significant explanatory variables. The relative food price index $\left(\dot{P}_{f r}\right)$ bears the incorrect sign in the presence of $\dot{P}_{m_{t-1}}$ and remains insignificant throughout. The credit to the government sector variable $\left(\dot{C}_{g_{t}}\right)$ bears a positive sign but remains insignificant.

The most striking outcome of the results reported in Table 3 is the crucial role played by the import price variables (used as a proxy of the foreign exchange constraint). $\dot{P}_{m_{t}}$ and $\dot{P}_{m_{t-1}}$ emerge as the dominant element in the inflationary process, they are highly significant in all sets of the equations exhibiting a significance level ranging between 0.1 and 2.5 percent. ${ }^{10}$ The importance of $\dot{P}_{m_{t-1}}$ is enhanced by the fact that its inclusion increases the overall explanatory power of the model by more than 20 percent and it is significant at the 0.1 percent level.

The introduction of $\dot{P}_{m_{t-1}}$ in Equations III and IV has important implications: in Equation III it reduces the size and significance of the coefficient of $y_{c_{t}}$, although it remains significant at the 5 percent level, implying that imports in the previous period helped to alleviate the supply-side constraints to some extent. Furthermore, in Equation IV while $y_{c_{t}}$ becomes insignificant in the presence of $\dot{P}_{t}^{e}$, the sharp decline in the size and significance of the coefficient of $\dot{P}_{t}^{e}$, which becomes insignificant in the presence of $\dot{P}_{m_{t-1}}$ implies that the availability of imports from the previous period would also tend to dampen the expectations of higher inflation by alleviating the domestic shortages of output.

With regard to the $\dot{C}_{g_{t}}$ variable it seems quite plausible to argue that the significance of this variable is captured by the import price variables. This is explained as follows: a larger proportion of government expenditure on commodity financing, mainly through imports, prevents the positive impact of $\dot{C}_{g_{t}}$ from becoming significant as increased availability through imports prevents sharp rises in prices. However, the import price variables themselves are highly significant throughout.

${ }^{10}$ In addition to the import price variable other variables like export instability index, quantum of imports, ratio of imports to GDP, real international reserves and ratio of reserves to imports (the last two variables have also been suggested by the referee) were also tested alternatively but none was found to be significant. Keeping in view the structuralist thesis that due to different underlying economic structures of LDCs a number of different variables may represent the given constraint for different individual countries, it is seen that in the test for structuralist hypothesis for Pakistan import price index is found to be the most satisfactory indicator of foreign exchange constraint. 
The insignificant coefficient of the relative food price index $\left(\dot{P}_{f r}\right)$ is not surprising. Since controls on the retail prices, especially of the food basket, have always been widespread in Pakistan the true impact of the food price increases is not reflected.

The coefficient of $y_{c_{t}}$ is highly significant in the absence of the expectations variable. However, with the introduction of $\dot{P}_{t}^{e}$ in Equation II, it becomes insignificant at the 5 percent level, $\dot{P}_{t}^{e}$ is significant at the 2.5 percent level and the explanatory power of the model is increased considerably. It implies that a decline in output in the current period gives rise to the expectations of higher inflation.

The outcome for the $y_{c_{t}}$ variable reflects the pattern of growth experienced by the economy of Pakistan. Over time, the share of the commodity-producing sectors, especially in the agricultural sector, has tended to decline while that of the services sector has increased. The decline in the productive sectors leading to higher inflation is the outcome of two factors: first the agricultural sector which provided the bulk of food and raw materials was strongly affected by the neglect in earlier years and adverse climatic conditions throughout the period under consideration. Second, the manufacturing sector which was largely geared to the production of consumer goods was affected both by domestic factors like labour unrest and nationalization, and sharp increases in the prices of raw materials and other essential inputs, and the recession in the world markets.

The results of the $y_{c_{t}}$ variable point to an important flaw in the use of total GNP as a measure of economic growth. The use of total GNP as an indicator of economic growth without due consideration to the composition of output between different sectors of the economy covers up the basic structural deficiencies underlying the economic system. In Pakistan, during the Sixties the growth rate of the commodity-producing sectors exceeded the growth rate of the services sector only during the Third Five Year Plan period (1965-70). For the period 1970-71 to 1981-82 the growth rate in the commodity-producing sectors exceeded the growth rate in the services sector only for two fiscal years (1975-76 and 1979-80). From 1970-71 to 1976-77 the commodity-producing sector registered an annual average growth rate of only 2.6 percent, which being less than the population growth rate of 3.7 percent implied a decline in the per capita availability of domestic final output during the Seventies. Furthermore, the faster growth of the services sector exacerbated the imbalances in the economy that resulted from an increasing demand unsupported by final output. The increasing demand, therefore, had to be met by higher imports and consequently by a rising price level due to sharp acceleration in the world prices of the LDC imports in general. The pattern of growth in the commodity-producing sectors generated expectations of higher inflation as is evident from the high inverse correlation between $y_{c_{t}}$ and $\dot{P}_{t}{ }^{{ }^{*}}{ }^{11}$ ${ }^{11}$ The correlation matrix shows that the coefficient of correlation between $\dot{p}_{t}^{e}$ and $y_{c_{t}}$
is $(0.602)$ significant at 1 percent level. 
To summarize, the results of the structuralist model bring out quite clearly that the economy has been affected by various structural constraints. The slow growth in output has been overcome by increased imports which have largely been facilitated through the increased flow of foreign exchange in the form of remittances from workers abroad. The results also suggest that a considerable part of the credit to the government sector may have been used for commodity-financing operations to supplement domestic output by purchases mainly of agricultural products from the domestic market in times of good harvest and through imports to prevent serious shortages.

\section{CONCLUSIONS AND POLICY IMPLICATIONS}

In this paper we have tested two alternative hypotheses of inflation - the monetarist hypothesis and the structuralist hypothesis, to study the inflationary process in Pakistan. The results of the study provide strong support to the 'relevancy' of the debate between the monetarists and the structuralists to the understanding of the problems of inflation in LDCs. Contrary to the monetarist assertion that inflation everywhere is a monetary phenomenon and can be controlled by controlling the money supply, the results of the monetarist model for Pakistan strongly suggest the need for a simultaneous consideration of the structural factors to identify more clearly the possible determinants of the inflationary process in Pakistan. The results of the structuralist model reflect quite closely the experience of the economy over time with respect to these constraints. The shortages in the commodity-producing sectors and higher import prices have a profound impact on the rate of inflation and the decline in output generates expectations of higher inflation.

The outcome of this study does not establish the superiority of one hypothesis over the other, rather it provides a much broader perspective of the complexities of the inflationary process in Pakistan. It also points towards some of the drawbacks of the domestic economic policies as well as the effects of external factors influencing the economy which were beyond the control of the government. 
function minimized at 1.245 . The high value of $\gamma=1.245$ implied that there was a specification bias in the model which failed to account for the underlying growth. To overcome this specification bias and capture the effect of growth trend we follow Friedman's (1957) specification used in the estimation of permanent income. He uses the equation of the form:

$$
Y P_{t}=\beta Y_{t}+(1-\beta)(1+c) Y P_{t-1} \quad \cdots \quad \ldots \quad \ldots
$$

where $\beta$ is the adjustment coefficient and $c$ is the trend rate of growth.

Following this specification we take:

$$
\dot{P}_{t}^{e}=\beta \dot{P}_{t-1}+(1-\beta)(1+c) \dot{P}_{t-1}^{e}{ }^{3}
$$

Using back substitution we get:

$$
\begin{aligned}
& \dot{P}_{t}^{e}=\beta \dot{P}_{t-1}+\beta[(1-\beta)(1+c)] \dot{P}_{t-2}+\beta[(1-\beta)(1+c)]^{2} \dot{P}_{t-3} \\
& \dot{P}_{t}^{e}=\beta \sum_{n=1}^{\alpha}[(1-\beta)(1+c)]^{n-1} \dot{P}_{t-n} \quad \cdots \quad \ldots . \quad \ldots
\end{aligned}
$$

and then generate the $\beta$ coefficient by using Equation (4) which becomes:

$$
L=\sum_{t=1}^{n}\left[\dot{P}_{t}-\dot{P}_{t}^{e}\right]=\sum_{t=1}^{n}\left[\dot{p}_{t}-\beta \sum_{n=1}^{\alpha}[(1-\beta)(1+c)]^{n-1} P_{t-n}\right]^{2}
$$

In finding the value of $\beta$ that minimizes the quadratic-loss function the number of terms in Equation (7) is again restricted to two to economize on the degrees of freedom. Repeating the search procedure adopted for $\gamma$ we obtain the value of $\beta$ that minimises $L$ in Equation (9) equal to 1.012 , which though still slightly greater than unity is significantly lower than the value of $\gamma$ in the Equation (4). The low value of $\beta=1.012$ may be taken to imply that expectations are static after accounting for the underlying trend growth rate. However for the sake of precision we generate the time series of the values for the expected rate of inflation by substituting the optimally chosen value of $\beta$ from Equation (9) into Equation (7).

${ }^{3}$ The trend rate $c$ are taken from estimating inflation trend equation: 


\section{REFERENCES}

Aghevli, B. B., and M. S. Khan (1978). "Government Deficit and Inflationary Process in Developing Countries". IMF Staff Papers. Vol. 25, No. 3.

Farrar, D. E., and R. R. Glauber (1967). "Multicollinearity in Regression Analysis: The Problem Revisited". Review of Economics and Statistics. Vol. XLIX, No. 1.

Firoze, Faiz B. (1986). "The Origins of Inflation in Pakistan 1959-82: An Evaluation of Alternative Hypothesis". Unpublished Ph.D. Thesis. Manchester: University of Manchester.

Fox, K. A. (1968). Intermediate Economic Statistics. New York: Wiley.

Friedman, M. (1957). A Theory of Consumption Function. National Bureau of Economic Research. Princeton, N.J.: Princeton University Press. (General Series LXIII)

Harberger, A. C. (1963). "The Dynamics of Inflation in Chile". In Carl Christ (ed.), Measurement in Economic Studies in Mathematical Economics. Stanford: Stanford University Press.

Kemal, A. R., F. Bilquees and A. H. Khan (1980). Estimates of Money Supply in Pakistan: 1959-60 to 1978-79. Islamabad: Pakistan Institute of Development Economics. (Statistical Papers Series, No. 1)

Mikesell, R. (1969). "Inflation in Latin-America". In C. Nisbet (ed.), LatinAmerica-Problems in Economic Development. New York: The Free Press. pp. 43-89.

Nugent, J. B., and Glezakos (1979). "A Model of Inflation and Expectations in Latin America". Journal of Development Economics. Vol. 6, No. 3.

Pakistan, Government of (Various Issues). Pakistan Economic Survey. Islamabad: Economic Adviser's Wing, Ministry of Finance.

Toyoda, T. (1972). "Price Expectations and the Short-run and Long-run Phillips Curves in Japan, 1956-68". Review of Economic and Statistics. Vol. LIV, No. 3 . 